\title{
Correction to: Public Policy in ALS/MND Care: The Belgian Perspective
}

\author{
Evy Reviers, Ludo Vanopdenbosch, Ludo Van Den Bosch, \\ and Philip Van Damme
}

\section{Correction to:}

Chapter 3 in: R. H. Blank et al. (eds.), Public Policy in ALS/MND Care, https://doi.org/10.1007/978-981-15-5840-5_3

The original version of this chapter was revised. Initially the title of this chapter was published as Public Policy in ALD/MND Care: ssThe Belgian Perspective. The correct title is Public Policy in ALS/MND Care: The Belgian Perspective.

An correction to this chapter can be found at https://doi.org/10.1007/978-981-15-5840-5_3

(C) The Author(s) 2021 